\title{
Contextual determinants of visual recognition with verbal and nonverbal stimuli
}

\author{
TIMOTHY A. SALTHOUSE and JOHN J. STERLING \\ University of Missouri, Columbia, Missouri 65201
}

\begin{abstract}
Two experiments were conducted to determine whether the presence of a meaningful nonverbal context (i.e., a schematic face) facilitates the recognition of an element (i.e., a facial feature) embedded in that context. Verbal stimuli (i.e., letters as elements and words as contexts) were also presented to provide a direct comparison of the context effects with the two types of stimuli. Although the verbal stimuli did not exhibit a context facilitation effect (i.e., letters presented in the context of a word were not recognized more accurately than letters presented alone), a significant interaction of Stimulus Type by Presentation Form resulted in both experiments because the nonverbal stimuli exhibited a context impairment effect (i.e., facial features presented in the context of a face were recognized less accurately than facial features presented alone).
\end{abstract}

Does the nature of the context within which a to-berecognized element is embedded influence the speed or accuracy at which that element is perceived or recognized? The results of many recent studies appear to provide a clearly affirmative answer to this question. Contextual facilitation effects have been reported in word recognition (e.g., Tulving, Mandler, \& Baumal, 1964), in letter recognition (e.g., Reicher, 1969; Wheeler, 1970), in letter-fragment recognition (e.g., Schendel \& Shaw, 1976), in object recognition (e.g., Biederman, Stacy, \& Glass, 1973; Palmer, 1975), and in line recognition (e.g., Weisstein \& Harris, 1974; Womersley, 1977).

However, a pilot experiment recently conducted in our laboratory employing schematic faces as stimuli yielded results in striking contradiction to these earlier studies. Subjects in this experiment were required to make same-different recognition judgments about the magnitudes of facial features presented alone or in the context of a face. The major result was that the judgment accuracy was substantially lower when the test feature was presented in the context of a face than when it was presented alone. Three experiments reported by Homa, Haver, and Schwartz (1976) also contained a finding of superior accuracy of identifying isolated facial elements compared to identifying the same elements embedded in the context of a face. Since these results suggest that a meaningful face context impairs rather than facilitates the recognition of embedded facial elements, it was decided to attempt to replicate this finding in a study that allowed a direct comparison of the effects of context with two types of material, verbal (i.e., letters and words) and nonverbal (i.e., facial features and faces).

This research was supported by a grant to the senior author from the Graduate School, University of Missouri.

\section{EXPERIMENT 1}

\section{Method}

Subjects. Thirty-two college students were paid to participate in a single session of approximately $1 \mathrm{~h}$.

Apparatus. The stimuli were presented under normal room illumination as slides projected on a viewing screen located approximately $240 \mathrm{~cm}$ from the subject. Both the face and word stimuli were sufficiently small (i.e., about $8 \mathrm{~cm}$ horizontally on the screen) that the visual angle of the entire display was between 1.5 and $2.5 \mathrm{deg}$, depending upon the subject's head position. A Kodak Carousel projector equipped with a Lafayette Model 43016 electronic tachistoscopic shutter was used to present the stimuli for either $1 / 150 \mathrm{sec}$ (for the verbal stimuli) or $1 / 50 \mathrm{sec}$ (for the nonverbal stimuli). Different exposure durations were used with the verbal and nonverbal stimuli in an attempt to produce approximately equivalent levels of performance.

The stimuli were either facial features, schematic faces, single letters, or four-letter words. The facial features were two different versions of eyes, ears, noses, and mouths. Two different sets of word stimuli were employed: a set derived from the base word "cane," and a set derived from the base word "beat." The single letters were lowercase versions of the letters c, s, a, o, n, m, e, and s for the "cane" base word, and $\mathrm{b}, \mathrm{h}, \mathrm{e}, \mathrm{o}, \mathrm{a}, \mathrm{n}, \mathrm{t}$, and $\mathrm{k}$ for the "beat" base word. When presented in context, the elements formed the words: cane, sane, cone, came, and cans for the cane set; and beat, heat, boat, bent, and beak for the beat set.

Procedure. A single stimulus item was presented tachistoscopically shortly after the subject reported he was prepared. Immediately after the presentation, the subject looked at a page in a notebook containing two alternatives (either facial features or faces in one condition, and letters or words in the other condition) from which he was required to choose the one that had been presented on that trial. The combination of two forms of stimulus presentation (element alone or element in context) with two forms of response alternatives (element alone or element in context) resulted in four distinct trial types for each set of stimuli. The four trial types were designated EE when both the presentation and the response alternatives were single elements, EC when the presentation was a single element, and the response alternatives were elements in context, $\mathrm{CE}$ when 
Table 1

Mean Percent Correct and Mean Confidence Ratings Across the Four Trial Types of Experiments 1 and 2

\begin{tabular}{|c|c|c|c|c|c|c|c|c|c|}
\hline & \multirow[b]{2}{*}{ Stimuli } & \multicolumn{2}{|c|}{ Element-Element } & \multicolumn{2}{|c|}{ Element-Context } & \multicolumn{2}{|c|}{ Context-Element } & \multicolumn{2}{|c|}{ Context-Context } \\
\hline & & PC & CR & PC & $\mathrm{CR}$ & PC & CR & PC & CR \\
\hline Experiment 1 & $\begin{array}{l}\text { Nonverbal } \\
\text { Verbal }\end{array}$ & $\begin{array}{l}67.2 \\
83.4\end{array}$ & $\begin{array}{l}1.71 \\
1.47\end{array}$ & $\begin{array}{l}67.2 \\
78.5\end{array}$ & $\begin{array}{l}1.67 \\
1.45\end{array}$ & $\begin{array}{l}52.7 \\
79.3\end{array}$ & $\begin{array}{l}2.30 \\
1.32\end{array}$ & $\begin{array}{l}52.2 \\
79.9\end{array}$ & $\begin{array}{l}2.26 \\
1.41\end{array}$ \\
\hline Experiment 2 & $\begin{array}{l}\text { Nonverbal } \\
\text { Verbal }\end{array}$ & $\begin{array}{l}75.9 \\
78.2\end{array}$ & $\begin{array}{l}1.62 \\
1.66\end{array}$ & $\begin{array}{l}73.2 \\
74.8\end{array}$ & $\begin{array}{l}1.68 \\
1.72\end{array}$ & $\begin{array}{l}65.5 \\
75.4\end{array}$ & $\begin{array}{l}1.77 \\
1.60\end{array}$ & $\begin{array}{l}69.2 \\
78.2\end{array}$ & $\begin{array}{l}1.78 \\
1.54\end{array}$ \\
\hline
\end{tabular}

Note $-P C=$ percent correct; $C R=$ confidence rating. Confidence ratings ranged from 1 , for "very confident," to 3 , for "just guessing." Reported values are from correct trials only and hence are independent of the percent-correct measure.

the presentation was an element in context and the response alternatives were single elements, and $\mathrm{CC}$ when both the presentation and the response alternatives were elements in context. The trial types within a given stimulus set were intermixed in a single block of 64 trials consisting of the four elements in the four trial types presented four times each, twice with the correct alternative on the left of the test page and twice with the correct alternative on the right.

Each subject received the face stimuli and one set of word stimuli. One-half of the subjects received the cane base-word stimuli and one-half the beat base-word stimuli. The order of presenting the face and word stimuli was counterbalanced across subjects.

The subjects responded by indicating which of the two response alternatives had been presented on that trial, and expressing the confidence they had in their decision by means of a number from one to three. A one indicated "very confident," a two "moderately confident," and a three indicated "just guessing."

\section{Results and Discussion}

Both the percent correct responses and the mean confidence ratings from correct trials were computed for each subject in each trial type with both sets of stimuli. Since only the confidence ratings for correct trials were analyzed, this measure can be treated as separate and independent from the percent-correct measure. The mean values of the two measures for the face and word stimuli across the 32 subjects are presented in the top two rows of Table 1. The values for the two sets of word stimuli were nearly identical with both dependent measures and hence they are pooled for simplicity.
The statistical significances of the effects apparent in Table 1 were assessed by means of three-factor (stimulus material, presentation form, and response alternatives form) analyses of variance on each variable. The pattern of results from both analyses was identical: significant effects of stimulus material [percent correct, $\mathrm{F}(1,31)=156.67, \quad \mathrm{p}<.0001 ; \quad$ confidence ratings, $\mathrm{F}(1,31)=136.35, \mathrm{p}<.0001]$, presentation form [percent correct, $F(1,31)=44.92, p<.0001$; confidence ratings, $F(1,31)=27.44, p<.0001]$, and of the interaction between stimulus material and presentation form [percent correct, $F(1,31)=25.31, p<.0001$; confidence ratings, $F(1,31)=95.56, p<.0001]$. No other effects except the subjects factor and interactions with the subjects factor were statistically significant $(p>.20)$.

A t test contrasting the confidence ratings for the verbal stimuli with isolated elements and with elements in context indicated that the subjects were significantly $[t(31)=2.19, p<.05]$ more confident when the letters were presented in words than when they were presented alone.

The effect of the context during presentation was also examined separately for each individual element. The mean percent-correct values are displayed in the first and third rows of Table 2 . An analysis of variance with the verbal stimuli revealed that the element factor was significant $[F(3,93)=3.93, p<.05]$, but the context factor was not $[F(1,31)<1.0]$. A similar analysis with the nonverbal stimuli indicated that the

Table 2

Mean Percent Correct for Each Element

\begin{tabular}{|c|c|c|c|c|c|c|c|c|}
\hline & \multicolumn{8}{|c|}{ Facial Feature } \\
\hline & \multicolumn{2}{|c|}{ Eyes } & \multicolumn{2}{|c|}{ Ears } & \multicolumn{2}{|c|}{ Nose } & \multicolumn{2}{|c|}{ Mouth } \\
\hline & EA & EC & EA & EC & EA & EC & EA & EC \\
\hline \multirow{4}{*}{$\begin{array}{l}\text { Experiment } 1 \\
\text { Experiment } 2\end{array}$} & $\begin{array}{l}73.8 \\
836\end{array}$ & 51.2 & 66.0 & $\begin{array}{l}50.4 \\
64.1\end{array}$ & $\begin{array}{l}63.7 \\
65.3\end{array}$ & $\begin{array}{l}51.2 \\
66.8\end{array}$ & $\begin{array}{l}63.3 \\
79.0\end{array}$ & $\begin{array}{l}56.6 \\
68.4\end{array}$ \\
\hline & \multicolumn{8}{|c|}{ Letter Position } \\
\hline & \multicolumn{2}{|c|}{1} & \multicolumn{2}{|c|}{2} & \multicolumn{2}{|c|}{3} & \multicolumn{2}{|c|}{4} \\
\hline & EA & EC & EA & EC & EA & EC & EA & EC \\
\hline $\begin{array}{l}\text { Experiment } 1 \\
\text { Experiment } 2\end{array}$ & $\begin{array}{l}78.1 \\
71.5\end{array}$ & $\begin{array}{l}79.3 \\
75.4\end{array}$ & $\begin{array}{l}76.1 \\
71.1\end{array}$ & $\begin{array}{l}76.6 \\
67.6 \\
\end{array}$ & $\begin{array}{l}89.5 \\
82.4 \\
\end{array}$ & $\begin{array}{l}81.6 \\
79.8 \\
\end{array}$ & $\begin{array}{l}80.1 \\
80.9 \\
\end{array}$ & $\begin{array}{l}80.9 \\
84.4 \\
\end{array}$ \\
\hline
\end{tabular}


element factor was not significant $[F(3,93)<1.0]$, but that the context factor was significant $[F(1,31)=$ $44.00, p<.0001]$. The Element by Context interaction just failed to reach significance in both analyses [verbal stimuli, $F(3,93)=2.27, .05<p<.10$; nonverbal stimuli, $\mathrm{F}(3,93)=2.49, .05<\mathrm{p}<.10]$.

The absence of a context facilitation effect with the verbal stimuli is probably attributable to the use of a known restricted set of response alternatives (e.g., Estes, 1975; Massaro, 1973), however, it might be caused by a lack of knowledge about the particular elements being tested on a specific trial. A second experiment was designed in which the response alternatives were presented both before and after the stimulus presentation to test this possibility.

\section{EXPERIMENT 2}

\section{Method}

Subjects. Thirty-two college students participated in a single session of approximately $1 \mathrm{~h}$.

Apparatus and Procedure. The equipment and materials were identical to that described in Experiment 1, and the same procedures were followed with the exception that the response alternatives were shown to the subject both before and after the stimulus presentation.

\section{Results and Discussion}

The data from this experiment are summarized in the bottom two rows of Table 1 and the second and fourth rows of Table 2 . In all major respects, these results replicated those of the previous experiment. The interaction of stimulus material with presentation form was significant with both percent-correct $[\mathrm{F}(1,31)=7.78$, $\mathrm{p}<.01]$ and confidence rating $[\mathrm{F}(1,31)=15.31$, $\mathrm{p}<.0005]$ measures. The only other significant effects with the exception of the subjects factor and interactions with the subjects factor were on the percentcorrect measure, namely, stimulus material $[F(1,31)=$ $11.06, \mathrm{p}<.005]$ and Presentation Form by Response Form $[F(1,31)=6.32, p<.05]$.

The difference between the confidence ratings for words and for letters was significant $[\mathrm{t}(31)=3.24$, $\mathrm{p}<.01$ ], again demonstrating that subjects are more confident when the verbal elements are embedded in a meaningful context than when they are presented in isolation.

The analyses with each individual element revealed that the element factor was significant with both sets of stimuli [verbal stimuli, $F(3,93)=10.30, p<.0001$; nonverbal stimuli, $F(3,93)=5.44, p<.005]$, and that the context factor $[F(1,31)=18.45, \mathrm{p}<.0005]$ and the Element by Context interaction $[\mathrm{F}(3,93)=3.12$, $\mathrm{p}<.05$ ] were significant for the nonverbal stimuli. No other effects, except the subjects factor and interactions with the subjects factor, were significant in either analysis.

\section{GENERAL DISCUSSION}

The results of Experiment 2 are quite consistent with those of Experiment 1, and lead to two well documented conclusions. First, a nonverbal target element in the context of a face is recognized less accurately and less confidently than an isolated target element. And second, a verbal target element in the context of a word is recognized just as accurately as an isolated target element, and with slightly more confidence. The confidence rating results with the verbal stimuli are interesting since they appear to be consistent with Estes' (1975) recent interpretation of context facilitation effects with verbal stimuli. His claim was that the performance difference between isolated elements and elements in context is caused by a difference in decision strategy and that "the advantage for words over single letters obtained under some circumstances should be found to represent primarily a criterion shift rather than a difference in signal-to-noise ratio" (Estes, 1975, p. 138). The greater confidence with the word stimuli relative to the letter stimuli may be interpreted as analogous to a difference in criterion independent of sensitivity, and thus this finding is evidence in favor of Estes' assertion.

Despite the finding that the verbal stimuli did not exhibit a context facilitation effect in these experiments, there was still a significant interaction of Stimulus Material by Presentation Form in both experiments. This suggests that, under the conditions of the present experiments, the verbal and nonverbal stimuli were handled by the subjects in different manners. Verbal elements can apparently be recognized just as accurately and rapidly in the context of other verbal elements as when viewed alone, but nonverbal elements cannot.

The analyses of the effects of context on individual elements revealed that the context impairment effect with nonverbal stimuli was stronger with some features than with others. In this respect, these results confirm those reported by Homa et al. (1976). However, there is no evidence in these data to support the Homa et al. claim that a context facilitation effect existed for some of the facial features. As the results in Table 2 indicate, in the only case where the isolated element was not recognized more accurately than the element in context (i.e., the nose feature in Experiment 2), the advantage of the context was only $1.5 \%$. We are therefore willing to accept the Homa et al. explanation of shifts in attention demands when the features are in the context of a face as being responsible for the different magnitudes of the context effects across features, but we contend that the context effects, when they occur, are always impairment effects and never facilitation effects.

\section{REFERENCES}

Biederman, I., Stacy, E. W., \& Glass, A. Searching for objects in real-world scenes. Journal of Experimental Psychology, 1973, 97, 22-27.

Estes, W. K. The locus of inferential and perceptual processes in letter identification. Journal of Experimental Psychology: General, 1975, 104, 122-145.

Homa, D., Haver, B., \& Schwartz, T. Perceptibility of schematic face stimuli: Evidence for a perceptual gestalt. Memory \& Cognition, 1976, 4, 176-185.

Massaro, D. W. Perception of letters, words, and nonwords. Journal of Experimental Psychology, 1973, 100, 349-353.

Palmer, S. E. The effects of contextual scenes on the identification of objects. Memory \& Cognition, 1975, 3, 519-526. 
ReICHER, G. M. Perceptual recognition as a function of the meaningfulness of the material. Journal of Experimental Psychology, 1969, 81, 275-280.

Schendel, J. D., \& Shaw, P. A test of the generality of the word superiority effect. Perception \& Psychophysics, 1976, 19. 383-392.

Tulving, E., Mandler, G., \& Baumal, R. Interaction of two sources of information in tachistoscopic word recognition. Canadian Journal of Psychology, 1964, 18, 62-71.
Weisstein, N., \& Harris, C. S. Visual detection of line segments: An object-superiority effect. Science, 1974, 186, $752-754$.

WheEler, D. D. Processes in word recognition. Cognitive Psychology, 1970, 1, 59-85.

Womersley, M. A contextual effect in feature detection with application of signal detection methodology. Perception \& Psychophysics, 1977, 21, 88-92.

(Received for publication October 24, 1977.) 